\title{
Effect of the Asthma-chronic obstructive pulmonary disease syndrome on the stroke, Parkinson's disease, and dementia: a national cohort study
}

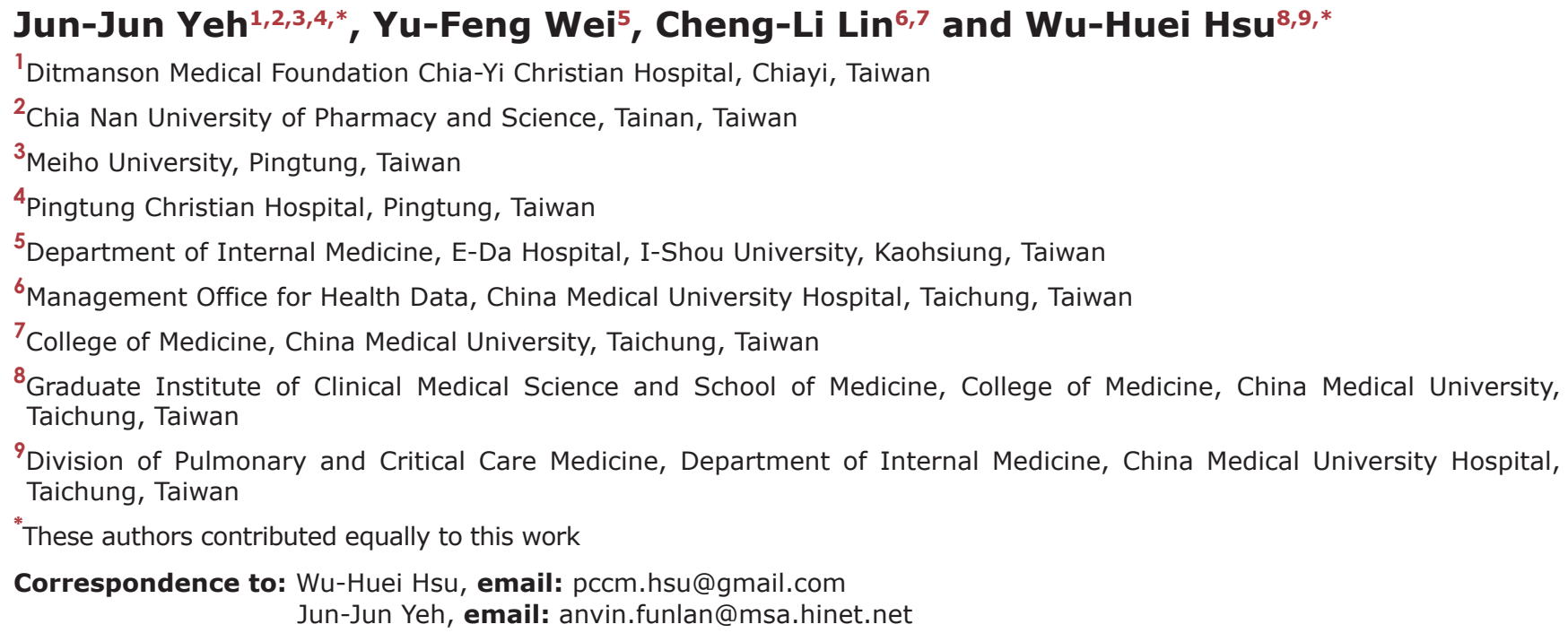

Keywords: asthma-chronic obstructive pulmonary disease syndrome (ACOS); stroke; Parkinson's disease (PD); dementia; inhaler steroids

Received: April 25, $2017 \quad$ Accepted: November 10, $2017 \quad$ Published: December 26, 2017

Copyright: Yeh et al. This is an open-access article distributed under the terms of the Creative Commons Attribution License 3.0 (CC BY 3.0), which permits unrestricted use, distribution, and reproduction in any medium, provided the original author and source are credited.

\section{ABSTRACT}

Background: To evaluate the association of asthma-chronic obstructive pulmonary disease syndrome (ACOS) with neurodegenerative diseases (stroke, Parkinson's disease and dementia) and the role of the steroids in the neurodegenerative diseases among the ACOS cohort.

Materials and Methods: Comparison of the ACOS cohort $(N=10,260)$ with the non-ACOS cohort $(n=20,513)$ based on the patients aged $\geqq \mathbf{4 0}$ years in the National Health Insurance Research Database from January 1, 2000 to December 31, 2010. These patients follow up to diagnosis of neurodegenerative diseases or the December 31, 2011; using multivariable Cox proportional hazards models.

Results: After adjustment for potential confounders, the [adjusted hazard ratio (aHR), 95\% confidence interval (CI)] in the ACOS cohort were [1.39, 1.28-1.50] $[1.56,1.34-1.81]$ and $[1.43,1.29-1.59]$ for stroke, Parkinson's disease, dementia; respectively. The [aHR, $95 \% \mathrm{CI}]$ for ACOS cohort with (inhaler corticosteroids $\geqq 0.13$ gram/ oral steroids $\geqq \mathbf{0 . 0 8 g r a m}$ ) were with less risk (all aHR<1, $p$ values $<0.05$ ) for these 3 neurodegenerative diseases except Parkinson's disease with inhaler corticosteroids $>0.43 \mathrm{gram}$. The risk of stroke and dementia were the lower in patients with $<250 \mu \mathrm{g} / \mathrm{d}$ of a fluticasone equivalent inhaler corticosteroids (aHR $=0.53,95 \%$ CI = 0.35-0.79; aHR =0.53, 95\% CI = 0.31-0.90, respectively).

Conclusions: The ACOS cohort had a higher risk of the neurodegenerative diseases. The lower dose of the inhaler corticosteroids with cumulative dose $\geqq 0.13$ gram have the less risk of stroke and dementia. 


\section{INTRODUCTION}

The increasing prevalence of frailty [1] is a concern in both developed and developing countries [2]. Frailty is associated with neurological disorders, such as stroke, dementia, and Parkinson's disease (PD) [3]. Stroke and dementia share many risk factors, including smoking-related diseases [e.g., diabetes, hypertension, hyperlipidemia, coronary artery disease (CAD), sleep disorder, cancer, tuberculosis (TB)] and alcoholrelated illness. All major dementias have a vascular component, and stroke increases the risk of dementia. Further interactions may relate the diseases, including the effect of blood pressure on amyloid development and stroke increased the risk of the amyloid inflammation [4]. Similarly, the amyloidosis deposit in the brain associated with the PD [5]. Therefore, these neurological inflammation diseases (PD, stroke, dementia) may concurrently occur in the same patients.

Neurodegenerative diseases, including PD, dementia with stroke [6]. PD may be caused by either genetic or environmental factors [7], and the mechanisms may include oxidative stress, or system inflammation. Oxidative stress is presumed to be the main mechanism of neurodegeneration [8]. The hypoxemia status causes the systemic inflammation, associated [9] with Interferon gamma (IFN $\gamma$ ), the tumor necrosis factor-alpha (TNF- $\alpha$ ) [10], and oxidative stress [11] leading to direct neuronal damage, as well as depletion of neurotransmitters because of the dysfunction of oxygen-dependent enzymes in chronic obstructive pulmonary disease (COPD) [12]. ACOS [13] is the concurrent occurrence of asthma [9] and COPD [14]. The high frequency of ACOS [15] with exacerbation aggravate systemic inflammation [12] and hypoxemia [16]. Therefore, the patients with ACOS may be associated with the neurodegenerative diseases $[9,16,17]$, especially these patients of asthma or COPD with exacerbation [18] and deterioration of hypoxemia [17-19]. This speculation didn't examined in detail up to today in English literature.

The inhaler corticosteroid (ICSs)/oral steroids (OSs) have the effect of the anti-inflammation and may attenuate the hypoxemia in ACOS [15]. But the relationship between the ICSs [20]/ OSs and the neurodegenerative diseases among the ACOS cohort [21] comparison with the non-ACOS cohort based on the general population were not found in previous study. Therefore, we examined the occurrence of neurodegenerative diseases [22] in the ACOS cohort, and the role of the ICSs/OSs [23] in the neurodegenerative diseases among the ACOS cohort comparison with the non-ACOS cohort. We tested these hypotheses in the general population.

\section{RESULTS}

We included 10,260 and 20,513 patients in the ACOS and non-ACOS cohorts, respectively, with similar sex and age distributions (Table 1). In both cohorts, 57.0\% of the patients were men and more than $55.1 \%$ of the patients were aged $\geq 65$ years. The mean age of patients in the ACOS and non-ACOS cohorts was 65.6 (SD = $11.8)$ and $65.5(\mathrm{SD}=11.9)$ years, respectively. Compared with the non-ACOS cohort, the ACOS cohort showed a higher prevalence of smoking-related comorbidities (e,g. diabetes, hypertension, hyperlipidemia, CAD, alcoholrelated diseases, anxiety, sleep disorder, pneumonia and TB) and atopic related diseases, except for cancer.

Overall, the ACOS cohort had higher incidence density rates of stroke (18.5 vs. 15.1 per 1000 personyears), PD (5.72 vs. 3.87 per 1000 person-years), and dementia (11.1 vs. 8.81 per 1000 person-years) than did the non-ACOS cohort, with a crude hazard ratio (cHR) of $1.23(95 \% \mathrm{CI}=1.15-1.32), 1.48(95 \% \mathrm{CI}=1.30-1.69)$, and $1.26(95 \% \mathrm{CI}=1.15-1.38)$, respectively (Table 2$)$. The Multivariable Cox proportional hazard regression analysis revealed a significantly higher risk of stroke in the ACOS cohort [adjusted HR $(\mathrm{aHR})=1.39,95 \% \mathrm{CI}=1.28$ $1.50]$ than in the non-ACOS cohort. Similar results were obtained for PD and dementia because the ACOS cohort showed a 1.56 -fold $(95 \% \mathrm{CI}=1.34-1.81)$ and 1.43 -fold $(95 \%$ CI $=1.29-1.59)$ higher risk of PD and dementia. After sex stratification, the relative risk of stroke in the ACOS cohort compared with the non-ACOS cohort was significantly higher in both women $(\mathrm{aHR}=1.38,95 \% \mathrm{CI}$ $=1.21-1.58)$ and men $(\mathrm{aHR}=1.38,95 \% \mathrm{CI}=1.24-1.53)$. The age-specific relative risk of stroke in both cohorts was higher in patients aged 40-65 (aHR $=1.34,95 \%$ $\mathrm{CI}=1.11-1.60)$ and $\geq 65$ years $(\mathrm{aHR}=1.37,95 \% \mathrm{CI}=$ 1.25-1.50). The risk of stroke was significantly increased in the ACOS cohort than in the non-ACOS cohort after the stratification of patients without any comorbidities (aHR $=1.64,95 \% \mathrm{CI}=1.21-2.22)$ and of those with at least one comorbidity $(\mathrm{aHR}=1.42,95 \% \mathrm{CI}=1.31-1.54)$. The risks of [PD and dementia], in ACOS cohorts aged $>65$ years $[(\mathrm{aHR}=1.56,95 \% \mathrm{CI}=1.33-1.83) ;(\mathrm{aHR}=1.42,95 \% \mathrm{CI}$ $=1.27-1.58)]$ or with comorbidity $[(\mathrm{aHR}=1.64,95 \% \mathrm{CI}$ $=1.42-1.91) ;(\mathrm{aHR}=1.54,95 \% \mathrm{CI}=1.38-1.71)]$ were higher than the non-ACOS cohorts. Figures $1 \mathrm{~A}-1 \mathrm{C}$ show the significantly higher cumulative incidence of stroke $(P<0.001$; Figure 1A), PD $(P<0.001$; Figure 1B), and dementia $(P<0.001$; Figure $1 C)$ in the ACOS cohort than in the non-ACOS cohort. In the interaction analysis, the patients without ICSs/OSs were at a higher risk of stroke, $\mathrm{PD}$, dementia compared to patients with ICSs/OSs (the $P$-value of interaction $<0.001$ ).

Table 3 presents the risks of stroke, PD, and dementia in patients with ACOS who used ICSs/OSs. The aHR $(95 \% \mathrm{CI})$ in patients with ACOS who received ICSs $<0.12$ gram were 1.08 (0.89-1.32); 1.81(1.33-2.46); $1.05(0.80-1.36)$ for stroke, PD and dementia. The aHR ( $95 \% \mathrm{CI})$ of the OSs $<0.07$ gram were 2.05 (1.87-2.26); 2.31 (1.96-2.73); $1.97(1.75-2.23)$ for the stroke, PD and dementia. The risk of the neurodegenerative diseases 
Table 1: Comparison of demographics and history of comorbidity between ACOS and non-ACOS cohorts

\begin{tabular}{|c|c|c|c|c|c|}
\hline \multirow[b]{3}{*}{ Variable } & \multicolumn{4}{|c|}{$\mathrm{ACOS}$} & \multirow[b]{3}{*}{$p$-value } \\
\hline & \multicolumn{2}{|c|}{ No $(N=20513)$} & \multicolumn{2}{|c|}{ Yes $(N=10260)$} & \\
\hline & $n$ & $\%$ & $n$ & $\%$ & \\
\hline Sex & & & & & 0.99 \\
\hline Female & 8826 & 43.0 & 4414 & 43.0 & \\
\hline Male & 11687 & 57.0 & 5846 & 57.0 & \\
\hline Age, year & & & & & 0.99 \\
\hline $40-49$ & 2470 & 12.0 & 1235 & 12.0 & \\
\hline $50-64$ & 6736 & 32.8 & 3368 & 32.8 & \\
\hline$\geq 65$ & 11307 & 55.1 & 5657 & 55.1 & \\
\hline $\operatorname{Mean}(\mathrm{SD})^{\#}$ & 65.5 & 11.9 & 65.6 & 11.8 & 0.38 \\
\hline \multicolumn{6}{|l|}{ Comorbidity } \\
\hline Diabetes & 4019 & 19.6 & 2425 & 23.6 & $<.0001$ \\
\hline Hypertension & 9659 & 47.1 & 6254 & 61.0 & $<.0001$ \\
\hline Hyperlipidemia & 5065 & 24.7 & 3271 & 31.9 & $<.0001$ \\
\hline Coronary artery disease & 5044 & 24.6 & 4065 & 39.6 & $<.0001$ \\
\hline Alcohol-related illness & 469 & 2.29 & 494 & 4.81 & $<.0001$ \\
\hline Sleep disorder & 3659 & 17.8 & 3063 & 29.9 & $<.0001$ \\
\hline Anxiety & 1371 & 6.68 & 1223 & 11.9 & $<.0001$ \\
\hline Atopic related diseases & 5586 & 27.2 & 4739 & 46.2 & $<.0001$ \\
\hline Cancer & 756 & 3.69 & 396 & 3.86 & 0.45 \\
\hline Tuberculosis & 466 & 2.27 & 782 & 7.62 & $<.0001$ \\
\hline Pneumonia & 1005 & 4.90 & 1785 & 17.4 & $<0.001$ \\
\hline \multicolumn{6}{|l|}{ Medicine } \\
\hline Inhaled corticosteroids (ICSs) & 652 & 3.18 & 2722 & 26.5 & $<.0001$ \\
\hline Oral steroids(OSs) & 8243 & 40.2 & 7941 & 77.4 & $<.0001$ \\
\hline
\end{tabular}

ACOS, asthma-COPD overlap syndrome; Chi-square test ; "Student's $t$-test.

were high with the OSs $<0.07$ gram and PD was higher with the ICSs $<0.012$ gram (the non-ACOS cohort as reference 1).

The ICSs with $0.13-0.43$ gram, the aHR $(95 \% \mathrm{CI})$ were $0.64(0.48-0.85) ; 0.53(0.29-0.97) ; 0.58(0.39-0.87)$ for the stroke, PD and dementia. The OSs with $0.08-0.26$ gram, the aHR $(95 \% \mathrm{CI})$ were $0.42(0.34-0.50), 0.30$ $(0.20-0.47), 0.44(0.34-0.56)$ for the stroke, PD and dementia. The ICSs with $>0.43$ gram, the aHR $(95 \%$ CI) were 0.57 (0.43-0.77), 0.65 (0.37-1.13), 0.55 (0.360.83 ) for the stroke, PD and dementia. The OSs with $>$ 0.26 gram, the aHR $(95 \% \mathrm{CI})$ were $0.63(0.52-0.75)$, $0.35(0.23-0.55), 0.51(0.39-0.66)$ for the stroke, PD and dementia. The risk of the degenerative diseases were less in the ACOS cohort except ICSs $>0.43$ gram for PD (the non-ACOS cohort as reference 1 ).
Without [ICSs; OSs], the aHR (95\% CI) were [1.43 (1.31-1.55), 1.59 (1.37-1.85)], [1.49 (1.34-1.66); 1.64 (1.46-1.85)], [1.98 (1.61-2.43), 1.78 (1.54-2.07)] for the stroke, PD, and dementia. The risk of the neurodegenerative diseases were higher in the ACOS cohort without OSs /ICSs (the non-ACOS cohort as reference 1).

Compared with the non-ACOS cohort, the risk of stroke and dementia were the lower in patients with lowdose use less than $250 \mu \mathrm{g} / \mathrm{d}$ of a fluticasone equivalent ICSs $(\mathrm{aHR}=0.53,95 \% \mathrm{CI}=0.35-0.79$; $\mathrm{aHR}=0.53,95 \%$ $\mathrm{CI}=0.31-0.90$, respectively). The ICSs with $[250 \mu \mathrm{g} / \mathrm{d}-500$ $\mu \mathrm{g} / \mathrm{d},>500 \mu \mathrm{g} / \mathrm{d}]$ of a fluticasone equivalent ICSs, the aHR $(95 \% \mathrm{CI})$ were $[0.70(0.47-1.04), 0.86(0.73-1.02)],[1.21$ (0.66-2.20); 1.09 (0.81-1.48)], [0.55 (0.31-1.01), 0.85 (0.67-1.07)] for the stroke, PD, and dementia. 
Table 2: Incidence rate and adjusted hazard ratio of stroke, Parkinson's disease, dementia between ACOS and non-ACOS cohorts stratified by sex, age, comorbidity (no/yes), and drug used (no/yes)

\begin{tabular}{|c|c|c|c|c|c|c|c|c|}
\hline \multirow[b]{3}{*}{ Variables } & \multicolumn{6}{|c|}{$\operatorname{ACOS}$} & & \\
\hline & \multicolumn{3}{|c|}{ No } & \multicolumn{3}{|c|}{ Yes } & \multicolumn{2}{|c|}{ Compared to non-ACOS cohort } \\
\hline & Event & PY & Rate & Event & PY & Rate & Crude HR (95\% CI) & Adjusted $\mathrm{HR} \uparrow(95 \% \mathrm{CI})$ \\
\hline \multicolumn{9}{|l|}{ Stroke } \\
\hline Overall & 2008 & 133159 & 15.1 & 1187 & 64030 & 18.5 & $1.23(1.15,1.32)^{* * *}$ & $1.39(1.28,1.50)^{* * * *}$ \\
\hline \multicolumn{9}{|l|}{ Sex } \\
\hline Female & 710 & 59618 & 11.9 & 456 & 28943 & 15.8 & $1.32(1.18,1.49)^{* * * *}$ & $1.38(1.21,1.58)^{* * * *}$ \\
\hline Male & 1298 & 73541 & 17.7 & 731 & 35088 & 20.8 & $1.18(1.08,1.29)^{* * *}$ & $1.38(1.24,1.53)^{* * * *}$ \\
\hline$p$ for interaction & & & & & & & & 0.13 \\
\hline \multicolumn{9}{|l|}{ Age, year } \\
\hline $40-65$ & 394 & 65268 & 6.04 & 276 & 32069 & 8.61 & $1.43(1.23,1.67)^{* * * *}$ & $1.34(1.11,1.60)^{* * *}$ \\
\hline$\geq 65$ & 1614 & 67891 & 23.8 & 911 & 31961 & 28.5 & $1.20(1.11,1.30)^{* * * *}$ & $1.37(1.25,1.50)^{* * * *}$ \\
\hline$p$ for interaction & & & & & & & & 0.16 \\
\hline \multicolumn{9}{|l|}{ Comorbidity } \\
\hline No & 338 & 44025 & 7.68 & 61 & 6797 & 8.97 & $1.16(0.88,1.52)$ & $1.64(1.21,2.22)^{* * *}$ \\
\hline Yes & 1670 & 89133 & 18.7 & 1126 & 57233 & 19.7 & $1.05(0.97,1.13)$ & $1.42(1.31,1.54)^{* * * *}$ \\
\hline$p$ for interaction & & & & & & & & 0.46 \\
\hline \multicolumn{9}{|l|}{ Drug used } \\
\hline No & 1240 & 78540 & 15.8 & 302 & 11675 & 25.9 & $1.63(1.43,1.85)^{* * *}$ & $1.50(1.30,1.71)^{* * * *}$ \\
\hline Yes & 768 & 54619 & 14.1 & 885 & 52355 & 16.9 & $1.20(1.09,1.32)^{* * *}$ & $1.17(1.06,1.29)^{* *}$ \\
\hline$p$ for interaction & & & & & & & & $<0.001$ \\
\hline \multicolumn{9}{|l|}{ Parkinson's disease } \\
\hline Overall & 532 & 137308 & 3.87 & 380 & 66438 & 5.72 & $1.48(1.30,1.69)^{* * * *}$ & $1.56(1.34,1.81)^{* * * *}$ \\
\hline \multicolumn{9}{|l|}{ Sex } \\
\hline Female & 200 & 61102 & 3.27 & 146 & 30030 & 4.86 & $1.49(1.20,1.84)^{* * *}$ & $1.47(1.15,1.88)^{* *}$ \\
\hline Male & 332 & 76206 & 4.36 & 234 & 36408 & 6.43 & $1.48(1.25,1.75)^{* * *}$ & $1.59(1.32,1.93)^{* * * *}$ \\
\hline$p$ for interaction & & & & & & & & 0.97 \\
\hline \multicolumn{9}{|l|}{ Age, year } \\
\hline $40-65$ & 74 & 66353 & 1.12 & 58 & 32910 & 1.76 & $1.58(1.12,2.23)^{* * *}$ & $1.45(0.96,2.17)$ \\
\hline$\geq 65$ & 458 & 70954 & 6.45 & 322 & 33528 & 9.60 & $1.49(1.29,1.72)^{* * * *}$ & $1.56(1.33,1.83)^{* * * *}$ \\
\hline$p$ for interaction & & & & & & & & 0.70 \\
\hline \multicolumn{9}{|l|}{ Comorbidity } \\
\hline No & 64 & 44702 & 1.43 & 11 & 6969 & 1.58 & $1.10(0.58,2.08)$ & $1.74(0.85,3.57)$ \\
\hline Yes & 468 & 92605 & 5.05 & 369 & 59469 & 6.20 & $1.23(1.07,1.41)^{* * *}$ & $1.64(1.42,1.91)^{* * * *}$ \\
\hline$p$ for interaction & & & & & & & & 0.74 \\
\hline \multicolumn{9}{|l|}{ Drug used } \\
\hline No & 328 & 81341 & 4.03 & 110 & 12325 & 8.92 & $2.21(1.78,2.74)^{* * * *}$ & $1.85(1.47,2.32)^{* * * *}$ \\
\hline Yes & 204 & 55967 & 3.64 & 270 & 54113 & 4.99 & $1.37(1.14,1.65)^{* * * *}$ & $1.30(1.08,1.57)^{* *}$ \\
\hline$p$ for interaction & & & & & & & & $<0.001$ \\
\hline \multicolumn{9}{|l|}{ Dementia } \\
\hline Overall & 1194 & 135558 & 8.81 & 726 & 65634 & 11.1 & $1.26(1.15,1.38)^{* * * *}$ & $1.43(1.29,1.59)^{* * * *}$ \\
\hline \multicolumn{9}{|l|}{ Sex } \\
\hline Female & 487 & 60223 & 8.09 & 298 & 29604 & 10.1 & $1.25(1.08,1.44)^{* * *}$ & $1.40(1.19,1.65)^{* * * *}$ \\
\hline Male & 707 & 75335 & 9.38 & 428 & 36031 & 11.9 & $1.27(1.13,1.43)^{* * *}$ & $1.44(1.26,1.65)^{* * * *}$ \\
\hline$p$ for interaction & & & & & & & & 0.84 \\
\hline \multicolumn{9}{|l|}{ Age, year } \\
\hline $40-65$ & 100 & 66337 & 1.51 & 79 & 32875 & 2.40 & $1.60(1.19,2.15)^{* * *}$ & $1.26(0.89,1.80)$ \\
\hline$\geq 65$ & 1094 & 69221 & 15.8 & 647 & 32759 & 19.8 & $1.26(1.14,1.39)^{* * * *}$ & $1.42(1.27,1.58)^{* * * *}$ \\
\hline$p$ for interaction & & & & & & & & 0.09 \\
\hline
\end{tabular}




\begin{tabular}{|c|c|c|c|c|c|c|c|c|}
\hline No & 194 & 44392 & 4.37 & 26 & 6908 & 3.76 & $0.85(0.56,1.28)$ & $1.38(0.88,2.17)$ \\
\hline Yes & 1000 & 91166 & 11.0 & 700 & 58727 & 11.9 & $1.09(0.99,1.20)$ & $1.54(1.37,1.71)^{*+* * t}$ \\
\hline$p$ for interaction & & & & & & & & 0.27 \\
\hline \multicolumn{9}{|l|}{ Drug used } \\
\hline No & 749 & 80234 & 9.34 & 204 & 12085 & 16.9 & $1.82(1.56,2.12)^{* * * *}$ & $1.61(1.37,1.90)^{* * * *}$ \\
\hline Yes & 445 & 55324 & 8.04 & 522 & 53549 & 9.75 & $1.22(1.07,1.38)^{* * *}$ & $1.18(1.04,1.35)^{*}$ \\
\hline$p$ for interaction & & & & & & & & $<0.001$ \\
\hline
\end{tabular}

ACOS, asthma-COPD overlap syndrome ;Drug used, including subjects with inhaled corticosteroids (ICSs) or oral steroids(OSs); PY, person-year; Rate, incidence rate (per 1,000 person-years); IRR, incidence rate ratio; Adjusted HR $\mathrm{H}^{\dagger}$ multiple cox model analysis including age, sex , each comorbidity, inhaled corticosteroid (ICSs), and oral steroids(OSs); ${ }^{*} p<0.05, " * * p<0.01,{ }^{* * * *} p<0.001$.

\section{DISCUSSION}

The ACOS cohort showed a higher risk of neurodegenerative diseases, namely stroke, PD and dementia regardless of age, sex, and comorbidities. These diseases were associated with cerebrovascular diseases [24]. Therefore, the risk of stroke was higher in patients with ACOS, even without comorbidities or when patients were young adults ( $\geqq 40$ years $<65$ years). Kumbhare et al. [25] reported stroke associated with relatively young adults of ACOS cohort in real world, consistent with our findings. Meanwhile, the ACOS cohort without ICSs/ OSs use have the higher risk of the neurodgenerative disaeases. Furthermore, the ACOS cohort with ICSs $>$ 0.13 gram or OSs $>0.08$ gram have the less risk of the neurodegenerative diseases. These findings imply that the ACOS associated with the risk of the neurodegenerative diseases; the ACOS with higher level of ICSs/OSs may have the less incidence of the neurodegenerative diseases.

Comorbidities (e.g. TB) [26] or alcohol consumption [27] were associated with the risk of PD. Meanwhile, atherosclerosis-related diseases (e.g. diabetes, hypertension, hyperlipidemia, CAD) and hypoxemiarelated diseases (e.g. pneumonia, sleep disorder) play a role for neurodegenerative diseases. The additive effect of the [29] alcohol-related diseases, atherosclerosisrelated diseases and hypoxemia-related diseases may have associated with the risk of neurodegenerative diseases. The higher risk of the neurodegenerative diseases in the ACOS with comorbidities in our study are in accordance with these previous findings [29].

Neurodegenerative diseases [30] and ACOS [31] were chronic inflammatory disease. The exact mechanisms between ACOS and neurodegenerative diseases are not clear, however it may partially be explained by coexistence of the systemic inflammation in both ACOS [32] and neurodegenertative diseases [33]. Several studies have reported an association between an increased atherosclerosis-related [34] inflammation markers [(e.g. TNF- $\alpha$ [33] and an increased risk of neurodegenerative diseases [32], including stroke [34], dementia and PD [35]. The level of TNF- $\alpha$ increased in the ACOS cohort [36] and its value is higher than the control groups [32]. This finding may support the inflammation markers associated with the neurodegenerative diseases.
Meanwhile, the IFN $\gamma$ may aggravate the astherosclerosis [24] and associated with the stroke [37] even in the lower level of the ACOS cohort compared with the control group [36]. Moreover, the IFN $\gamma$ with the synergistic contribution of TNF- $\alpha$ in PD [38]. These speculations may explain the risks of the stroke with young age $(\geqq 40$ years $<65$ years) and stroke, $\mathrm{PD}$, dementia with elderly ( $>65$ years) in ACOS cohort were higher than the non-ACOS cohort in our study. However, no significant differences of the risk of the PD and dementia in the ACOS cohort with the aged $>40$ years $<65$ years. The role of the cytokine in the different subgroup ( $\geqq 40$ years $<65$ years, $>65$ years) of the neurodegenerative diseases among the ACOS cohort warrant further study.

Meanwhile, as previous mention [39-41], the oxidative stress of the chronic obstructive airway disease associated neurodegenerative diseases [39]. Similarly, the severe form of the ACOS with high frequency of $\mathrm{AE}$ and the hospitalization [16]; thus, the intermittent hypoxemia [42] and oxidative stress aggravate the exists the atherosclerosis [34] of system artery (e.g. carotid artery). Furthermore, the hypercapnia may have impact on the dementia and ventilator impairment in the PD [43]. These vehicle cycle may enhance the hypoxemia/ hypercapnia [44]; thus, the incident of neurodegenerative diseases increased. The aging [45] and atherosclerosisrelated diseases of ACOS cohort are associated with the system inflammation [31] also. Considering these speculations [30, 35, 39]; aging, hypoxemia [16, 42] and system inflammation [14,31] are predisposing factors [33] for neurodegenerative diseases (e.g. stroke) even without the comorbidities.

The ICSs may be administered for treating the mild to moderate type of ACOS [13, 46]. The ICSs [47] may improve poor lung function [28]; thus, attenuating the hypoxemia level [48]. In a korea [49] and Japan [50] study shows ACOS shows the possibility of recovering their lung function under ICSs in line with this finding. Meanwhile, ACOS seems to be more responsive to bronchodilators [51] and ICSs [52] compared with the pure COPD cohort. In Feng et al, study [52], they found that ICSs (e.g. 2 $\mathrm{mg} \times 3 /$ day $\times 180$ days $=1.08$ gram) may attenuate the inflammation, hypoxemia, and hypercarpenia. These findings support the ICSs $>0.13$ gram in ACOS cohort may attenuate the airway and system inflammation. Thus, 
Table 3: The association between ACOS and drug day (per year) and average dose (per year) of ICSs, OSs, and antibiotic therapy for the risk of stroke, Parkinson's disease, dementia

\begin{tabular}{|c|c|c|c|c|c|}
\hline Variables & $\mathbf{N}$ & Event & Rate & Crude HR $(95 \%$ CI) & Adjusted HR $(95 \% \text { CI })^{\dagger}$ \\
\hline \multicolumn{6}{|l|}{ Stroke } \\
\hline Non-ACOS cohort & 20513 & 2008 & 15.1 & 1.00 & 1.00 \\
\hline \multicolumn{6}{|l|}{ ACOS cohort } \\
\hline Without ICSs & 7538 & 984 & 21.7 & $1.44(1.34,1.56)^{* * * *}$ & $1.43(1.31,1.55)^{* * * *}$ \\
\hline \multicolumn{6}{|l|}{ With ICSs (gram), per year } \\
\hline$\leq 0.12$ & 910 & 105 & 14.4 & $0.95(0.78,1.16)$ & $1.08(0.89,1.32)$ \\
\hline $0.13-0.43$ & 869 & 52 & 8.60 & $0.57(0.43,0.75)^{* * * *}$ & $0.64(0.48,0.85)^{* * *}$ \\
\hline$>0.43$ & 1853 & 46 & 8.55 & $0.57(0.42,0.76)^{* * * *}$ & $0.57(0.43,0.77)^{* * * *}$ \\
\hline Non-ACOS cohort & 20513 & 2008 & 15.1 & 1.00 & 1.00 \\
\hline \multicolumn{6}{|l|}{ ACOS cohort } \\
\hline Without OSs & 2319 & 326 & 24.3 & $1.61(1.43,1.81)^{* * * *}$ & $1.64(1.46,1.85)^{* * * *}$ \\
\hline \multicolumn{6}{|l|}{ With OSs (gram), per year } \\
\hline$\leq 0.07$ & 2573 & 619 & 33.0 & $2.19(2.00,2.40)^{* * * *}$ & $2.05(1.87,2.26)^{* * * *}$ \\
\hline $0.08-0.26$ & 2650 & 109 & 5.97 & $0.40(0.33,0.48)^{* * * *}$ & $0.42(0.34,0.50)^{* * * *}$ \\
\hline$>0.26$ & 2718 & 133 & 9.80 & $0.65(0.55,0.77)^{* * * *}$ & $0.63(0.52,0.75)^{* * * *}$ \\
\hline Non-ACOS cohort & 20513 & 2008 & 15.1 & 1.00 & 1.00 \\
\hline \multicolumn{6}{|l|}{ ACOS cohort } \\
\hline Without ICSs & 7538 & 984 & 21.7 & $1.44(1.34,1.56)^{* * * *}$ & $1.42(1.30,1.54)^{* * * *}$ \\
\hline \multicolumn{6}{|l|}{ ICSs (fluticasone equivalent) } \\
\hline Low dose $(<250$ ug/d) & 451 & 24 & 6.65 & $0.44(0.30,0.66)^{* * * *}$ & $0.53(0.35,0.79)^{* * *}$ \\
\hline Middle dose (250-500 ug/d) & 375 & 25 & 9.72 & $0.64(0.43,0.96)^{*}$ & $0.70(0.47,1.04)$ \\
\hline High dose (>500 ug/d) & 1896 & 154 & 12.3 & $0.82(0.69,0.96)^{*}$ & $0.86(0.73,1.02)$ \\
\hline \multicolumn{6}{|l|}{ Parkinson's disease } \\
\hline Non-ACOS cohort & 20513 & 532 & 3.87 & 1.00 & 1.00 \\
\hline \multicolumn{6}{|l|}{ ACOS cohort } \\
\hline Without ICSs & 7538 & 309 & 6.52 & $1.69(1.47,1.94)^{* * * *}$ & $1.59(1.37,1.85)^{* * * *}$ \\
\hline \multicolumn{6}{|l|}{ With ICSs (gram), per year } \\
\hline$\leq 0.12$ & 910 & 47 & 6.28 & $1.61(1.19,2.17)^{* * *}$ & $1.81(1.33,2.46)^{* * * *}$ \\
\hline $0.13-0.43$ & 869 & 11 & 1.80 & $0.46(0.26,0.84)^{*}$ & $0.53(0.29,0.97)^{*}$ \\
\hline$>0.43$ & 1853 & 13 & 2.40 & $0.62(0.36,1.08)$ & $0.65(0.37,1.13)$ \\
\hline Non-ACOS cohort & 20513 & 532 & 3.87 & 1.00 & 1.00 \\
\hline \multicolumn{6}{|l|}{ ACOS cohort } \\
\hline Without OSs & 20513 & 532 & 3.87 & $2.12(1.74,2.60)^{* * * *}$ & $1.98(1.61,2.43)^{* * * *}$ \\
\hline \multicolumn{6}{|l|}{ With OSs (gram), per year } \\
\hline$\leq 0.07$ & 2573 & 218 & 10.8 & $2.77(2.36,3.24)^{* * * *}$ & $2.31(1.96,2.73)^{* * * *}$ \\
\hline $0.08-0.26$ & 2650 & 23 & 1.25 & $0.32(0.21,0.49)^{* * * *}$ & $0.30(0.20,0.47)^{* * * *}$ \\
\hline$>0.26$ & 2718 & 23 & 1.68 & $0.44(0.29,0.67)^{* * * *}$ & $0.35(0.23,0.55)^{* * * *}$ \\
\hline Non-ACOS cohort & 20513 & 532 & 3.87 & 1.00 & 1.00 \\
\hline \multicolumn{6}{|l|}{ ACOS cohort } \\
\hline Without ICSs & 7538 & 309 & 6.52 & $1.69(1.47,1.94)^{* * * *}$ & $1.59(1.36,1.85)^{* * * *}$ \\
\hline \multicolumn{6}{|l|}{ ICSs (fluticasone equivalent) } \\
\hline Low dose $(<250 \mathrm{ug} / \mathrm{d})$ & 451 & 10 & 2.75 & $0.71(0.38,1.32)$ & $0.83(0.44,1.55)$ \\
\hline Middle dose (250-500 ug/d) & 375 & 11 & 4.22 & $1.09(0.60,1.98)$ & $1.21(0.66,2.20)$ \\
\hline High dose (>500 ug/d) & 1896 & 50 & 3.91 & $1.01(0.76,1.35)$ & $1.09(0.81,1.48)$ \\
\hline \multicolumn{6}{|l|}{ Dementia } \\
\hline Non-ACOS cohort & 20513 & 1194 & 8.81 & 1.00 & 1.00 \\
\hline \multicolumn{6}{|l|}{ ACOS cohort } \\
\hline Without ICSs & 7538 & 619 & 13.3 & $1.52(1.38,1.67)^{* * * *}$ & $1.49(1.34,1.66)^{* * * *}$ \\
\hline
\end{tabular}




\begin{tabular}{|c|c|c|c|c|c|}
\hline \multicolumn{6}{|l|}{ With ICSs (gram), per year } \\
\hline$\leq 0.12$ & 910 & 59 & 7.93 & $0.88(0.68,1.15)$ & $1.05(0.80,1.36)$ \\
\hline $0.13-0.43$ & 869 & 25 & 4.10 & $0.47(0.31,0.69)^{* * * *}$ & $0.58(0.39,0.87)^{* *}$ \\
\hline$>0.43$ & 1853 & 23 & 4.25 & $0.49(0.32,0.74)^{* * * *}$ & $0.55(0.36,0.83)^{* *}$ \\
\hline Non-ACOS cohort & 20513 & 1194 & 8.81 & 1.00 & 1.00 \\
\hline \multicolumn{6}{|l|}{ ACOS cohort } \\
\hline Without OSs & 2319 & 213 & 15.3 & $1.76(1.52,2.04)^{* * * *}$ & $1.78(1.54,2.07)^{* * *}$ \\
\hline \multicolumn{6}{|l|}{ With OSs (gram), per year } \\
\hline$\leq 0.07$ & 2573 & 383 & 19.4 & $2.17(1.93,2.43)^{* * * *}$ & $1.97(1.75,2.23)^{* * *}$ \\
\hline $0.08-0.26$ & 2650 & 67 & 3.65 & $0.42(0.33,0.53)^{* * *}$ & $0.44(0.34,0.56)^{* * * *}$ \\
\hline$>0.26$ & 2718 & 63 & 4.62 & $0.54(0.42,0.69)^{* * * *}$ & $0.51(0.39,0.66)^{* * * *}$ \\
\hline Non-ACOS cohort & 20513 & 1194 & 8.81 & 1.00 & 1.00 \\
\hline \multicolumn{6}{|l|}{ ACOS cohort } \\
\hline Without ICSs & 7538 & 619 & 13.3 & $1.52(1.38,1.67)^{* * *}$ & $1.48(1.33,1.65)^{* * * *}$ \\
\hline \multicolumn{6}{|l|}{ ICSs (fluticasone equivalent) } \\
\hline Low dose $(<250$ ug/d $)$ & 451 & 14 & 3.86 & $0.43(0.25,0.73)^{* * *}$ & $0.53(0.31,0.90)^{*}$ \\
\hline Middle dose (250-500 ug/d) & 375 & 11 & 4.20 & $0.48(0.26,0.86)^{*}$ & $0.55(0.31,1.01)$ \\
\hline High dose (>500 ug/d) & 1896 & 82 & 6.45 & $0.73(0.59,0.92)^{* * *}$ & $0.85(0.67,1.07)$ \\
\hline
\end{tabular}

ACOS, asthma-COPD overlap syndrome; the average use day on median use is partitioned in to 2 segments by median; the average dose on median use is partitioned in to 3 segments by tertile; Rate, incidence rate (per 1,000 person-years); IRR, incidence rate ratio; Adjusted HR ${ }^{\dagger}$ : multiple cox model analysis including age, sex , each comorbidity, inhaled corticosteroid (ICSs), oral steroid(OSs); ${ }^{*} p<0.05,{ }^{* *} p<0.01,{ }^{* * *} p<0.001$.

the incidences of the neurodegenerative diseases were less in the ACOS cohort comparison of the non-ACOS cohort. Similarly, Liu et al, report the ICSs (e.g. > 0.0395 gram) have the impact on attenuation of the chronic system inflammation in the COPD support this finding [53].

Impaired lung function is an independent predictor of cognitive diseases, such as dementia; however, evidence of its association with cognitive decline is mixed [54]. The OSs $[16,55]$ are used for treating the relatively severe type [55] of ACOS [13, 20]. This type involves poor lung function and more severe hypoxemia [27]. However, the eosinophilic inflammation induced by ACOS responded well to OSs. Therefore, adequate dose of the OSs use may reduce hypoxemia [56], and patients receiving steroids may have a lower risk [16] of atherosclerosis of the blood vessels [16] or amyloidosis of the brain [4]. The effect of the pulse predinsolone dose of 5 days $(40 \mathrm{mg} /$ days $\times 5$ days $=200$ $\mathrm{mg}$ ) [57] to 14 days $(560 \mathrm{mg})$ attenuate the AE-COPD in previous study support this speculation [58]. In addition, the pulse therapy of the steroid such as dexamethasone [59] or corticosteroid [60] in previous studies may play a role in the protective effect of the dementia and PD support with these results. The use of OSs with $>0.08$ gram $(80 \mathrm{mg})$ were associated with the less risk of neurodegenerative diseases in our study agree these findings.

The use of OSs with $<0.07$ gram [57] were associated with the higher risk of neurodegenerative diseases. Meanwhile, the ICSs $<0.12$ gram were associated with the higher risk of PD. This imply that the small dose of steroid without effect on the risk of the neurodegenerative diseases. Moreover, the ACOS cohort without the ICSs / OSs were with the higher risk of the neurodegenerative diseases. In previous study, the optimal higher level dose of the dexamethasone $0.001 \mathrm{gram} / \mathrm{kg}$ (equlvalent to 0.0067 gram prednisolone $/ \mathrm{kg}$, e.g., 0.0067 gram $\times 50 \mathrm{~kg}=$ 0.335 gram $>0.08$ gram) diminished a dopamine content depletion in striatum by about $20 \%$, whereas the lower doses of $0.0001 \mathrm{gram} / \mathrm{kg}(0.0335$ gram was $<0.08$ gram $)$ ineffective $[53,59]$, this report is in line with our result. Meanwhile, the lower level of the ICSs ( e.g. $<0.0395$ grams) didn't attenuate the chronic system inflammation among the COPD in observer study [53]. Similarly, the higher cumulative dose of ICSs $(1.2 \mathrm{mg} /$ day x 180day $=0.21$ gram $>0.13$ gram) have a protective effect of the system inflammation (IFN $\gamma, \mathrm{TNF}-\alpha$ ), [61] in COPDrelated disease such as lung cancer [62], this protective effect was not found in the lower dose $(<0.21$ gram). Therefore, protective effect of ACOS combined with the higher levels of ICSs/OSs, and the risky effects of ACOS combined with the lower levels ICSs/OSs for system inflammation diseases-neurodegenerative diseases such as in current study. Similarly, in Yamauchi et al study, it appears that greater amounts of administered OSs/ICSs [63] are related to better prognosis in the ACOS cohort than in the COPD-alone cohort [64]. These speculations in need of randomized, double-blind, placebo-controlled pilot trial for confirmation.

Regarding the daily dose of the of a fluticasone equivalent ICSs [65], we found the dose [250 $\mu \mathrm{g} / \mathrm{d}-500$ $\mu \mathrm{g} / \mathrm{d}(0.25 \mathrm{mg} / \mathrm{d}-0.5 \mathrm{mg} / \mathrm{d})$ and $>500 \mu \mathrm{g} / \mathrm{d}(0.5 \mathrm{mg} / \mathrm{d})]$ without association with the risk of the neurodegenerative diseases. Meanwhile, we also found the risk of stroke and dementia were the lower in patients with low-dose use less than $250 \mu \mathrm{g} / \mathrm{d}(0.25 \mathrm{mg} / \mathrm{d})$ of a fluticasone equivalent ICSs [66]. As mention before, ICSs $>0.13$ gram in ACOS cohort may attenuate the airway and system inflammation. 
Therefore, if we use the low dose of the ICSs up to 521 days, the cumulative dose of ICSs is $>130 \mathrm{mg}[(0.13$ gram) $/ 0.25 \mathrm{mg} / \mathrm{d}=520$ days]. Thus, the ACOS cohort may have the less risk of the stroke and dementia. In versa, if we use the middle or high daily dose ICSs for the severe ACOS cohort with relatively short period (e.g., 240 days); thus, we shift the ICSs to OSs (e.g., from the day 241). Under this policy, the cumulative dose of ICSs with 130 $\mathrm{mg}(0.13$ gram $)$ is inaviable (e.g., $0.5 \mathrm{mg} / \mathrm{d} \times 240 \mathrm{~d}=120$ $\mathrm{mg}<0.13$ gram). Thus, the high daily dose (high up to $500 \mu \mathrm{g} / \mathrm{d}$ ) with 240 days without significant impact on the risk of the neurodegenerative diseases. This imply that impact for the 'dose-response' is more efficient of the 'cumulative dose' than of the 'daily dose' between the ICSs and neurodegenerative diseases among the ACOS cohort comparison of the non-ACOS cohort. These speculations warrant randomized control trial for confirmation.
This finding of our study may alert the cliclican to early detect the ACOS [67] among the COPD or asthma groups, and we may try the adequate dose of the ICSs/OSs (e.g. minimal effect dose 0.13 grams $/ 0.08$ grams) within optimal duration (e.g., high dose in 5-7 days for OSs [57] in exacerbation of ACOS, lower dose of ICSs in daily care of ACOS for 520 days or more [52]) for avoiding the risk of the neurodegenerative diseases in the late course of the ACOS cohort. In practice, this finding imply the low dose of $[0.25 \mathrm{mg} / \mathrm{d}$ of a fluticasone equivalent ICSs] combined with long course (e.g., 520 days) of ICSs may have the less incidence of the stroke and dementia. However, the steroid [68] may have the less effect on the attenuation of the hypoxemia in the steroid-resistant in asthma [69] or ACOS $[20,68]$. Nevertheless, the large dose of steroid is a predisposing factor of the adverse reaction such as hypertension. Take into these findings together, the
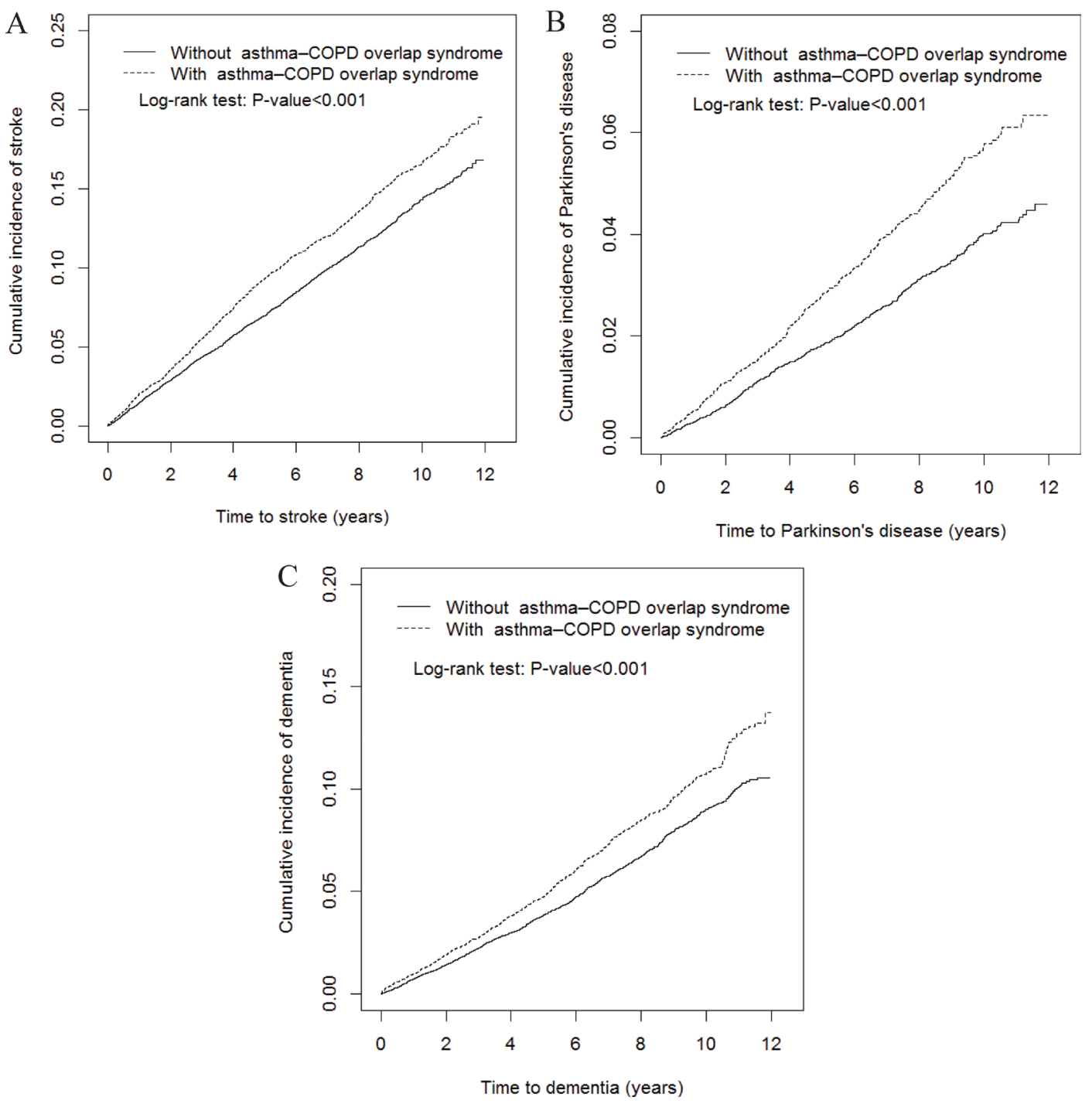

Figure 1: The cumulative incidence of stroke (A), Parkinson's disease (B), dementia $(\mathbf{C})$ in asthma-COPD overlap syndrome (ACOS) (dashed line) and non-ACOS cohorts (solid line). 
adequate dosage of steroid and the optimal duration of the steroid use warrant needs urgent resolution in future [70].

\section{Strengths}

In ACOS cohort of our study, the mean age is 65.6 years [25], 26.5\% with ICSs and $77.4 \%$ with OSs use imply that the largely portion of these patients fit the criteria of the steroid use (post-bronchodilator increase in the forced expiratory volume in one second (FEV1) $>12 \%$ and $>200-400 \mathrm{ml}$ from baseline) [71] which is a major component of the ACOS [68]. These characterization in line with the recent study of the ACOS in general population [72]. According to our review of relevant literature published in the English language, this study is the first to focus on the bridging the neurodegenerative diseases with the ACOS. Neurodegenerative diseases and ACOS are diagnosed using a well-established system. In this study, we analyzed patients with smoking- and alcohol-related lifestyle diseases; we enrolled patients with atopic-related diseases, which are related to ACOS also. Moreover, we considered the use of drugs, such as OSs, ICSs. The analysis were based on the combination of ACOS and ICSs/OSs use may avoid diagnosis-related bias. This novel finding warrant further investigation.

\section{Limitations}

ACOS diagnosis is challenging for physicians. However, our study cohort was derived from the COPD cohort; more than half of the COPD diagnosis was based on the pulmonary function test (PFT) conducted in Taiwan [14]. COPD diagnosis is the result of a holistic decision-making strategy that takes into account medical history, risk factors, physical examination, spirometry, radiographic examinations and longterm response to inhaled bronchodilators and/or corticosteroids [73]. Either diagnosed COPD with PFT or COPD without PFT having related respiratory symptoms (breathlessness, ongoing cough, cough with sputum, wheezing, and chest tightness) of 3 months duration that also fulfill an epidemiological case definition of COPD [74]. In addition, the largely portion of the patients of ACOS cohort received the ICSs/OCSs. The [ICDcohort + COPD medicine] may avoid the bias of diagnosis of COPD [75]. However, the justifications such as clinical symptoms, office spirometry, the patients received the true dosage of the medicine and specialist's correspondence may be the limitations in this study [76]. Meanwhile, we replace the current smoking status or smoking index which were unavailable in the NHIRD by the smoking-related disease (e.g. comorbidities). In addition, the classify the dementia and PD may challenge the clinical physician. The pathology of the neurodegenerative diseases were unavailable in the NHIRD also. These points may be a cofounder for misclassification of dementia and PD. Furthermore, antihypertensive and oral hypoglycemic drugs may affect the neurodegenerative diseases. We did not analyze the effects of these drugs in this study. Thus, the role of OSs, ICSs in the neurodegenerative diseases warrant randomized controlled trials in other country for confirmation.

Campbell and Stanley (1963) delineated two types of validity: internal validity as a characteristic of the experimental treatment effect [77], and external validity that provides the basis for generalizability to other populations, settings, and times. First, issues related to the external validity of trials $[78,79]$ involving patients with multiple chronic conditions (stroke, PD, and dementia) of this study addressed to other area including: 1) patient factors: lack of clarity around participant inclusion and definitions if the setting didn't have the strict NHIRD, heterogeneity and age of participants with multiple chronic conditions. 2) system factors: chronic disease interventions designed around single conditions, Secondly; patient populations (age $>20,<40$ years vs. age $>40$ years) and clinicians (chest physician vs. neurologist) will be quite different in different settings. Thirdly; regarding the drug treatment, 1) Pretest-Treatment-Pretesting may sensitize the experimental subjects to the experimental factor so the results obtained can be generalized only to other pretested groups (e.g. the patients with expericine of ICSs/OSs). 2) MultipleTreatment Interaction/Interference: subjects received more than one treatment (the patients with ICSs/OSs) [80]. 3) Selection-Treatment Interaction: the effect of the treatment of patients aged $>40$ years cant not be addressed to patients $<40$ years. 4) the education level of the patients living in the country is different from the city. 5) Specificity of variables: the different measuring methods of evaluation the progress of the ACOS change over time [81]. 6) Experimenter Effects: the patients received the management under the different chest physician with different dose of ICSs/OSs. 7) Reactive Arrangements: subjects may react according to their knowledge of the experiment (e.g. the skill of inhaler use among the patients enrolled into study)[78].

\section{MATERIALS AND METHODS}

\section{Data source}

Data were retrieved from Taiwan's Longitudinal Health Insurance Database 2000 (LHID2000), an insurance claim database of Taiwan's National Health Insurance (NHI) program launched in 1995 . The NHI covers $99 \%$ of the Taiwanese population (approximately 24 million residents) and releases the NHI Research Database (NHIRD). The LHID2000 randomly selected 1,000,000 insurants enrolled in the NHI program from 1996 to 2000 and traced their medical utilization. Details of the LHID2000 and NHI program have been described elsewhere [82].

\section{Data availability statement}

The dataset used in this study is held by the Taiwan Ministry of Health and Welfare (MOHW). 
The MOHW must approve our application to access this data. Any researcher interested in accessing this dataset can submit an application form to the MOHW requesting access. Please contact the staff of MOHW (Email: stcarolwu@mohw.gov.tw) for further assistance. Taiwan MOHW Address: No.488, Sec. 6, Zhongxiao E. Rd., Nangang Dist., Taipei City 115, Taiwan (R.O.C.). Phone: +886-2-8590-6848. All relevant data are within the paper.

\section{Ethics statement}

The NHIRD encrypts patient personal information to protect privacy and provides researchers with anonymous identification numbers associated with relevant claims information, including sex, date of birth, medical services received, and prescriptions. Therefore, patient consent is not required to access the NHIRD. This study was approved to fulfill the condition for exemption by the Institutional Review Board (IRB) of China Medical University Hospital (CMUH104-REC2-115-CR2). The IRB also specifically waived the consent requirement.

\section{Study design and participants}

We recruited patients with new diagnosis of the COPD [International Classification of Diseases, Ninth Revision, Clinical Modification (ICD-9-CM) 491, 492, and 496) who were aged $\geq 40$ years [13] and had concurrent physician-diagnosed new asthma (ICD-9-CM 493) [72] from January 1, 2000 to December 31, 2010 in the ACOS cohort. These patients diagnosed as having asthma in $\geq 3$ outpatient and/or hospitalizations visits and COPD in $\geq 3$ outpatient and/or hospitalizations visits. The index date was defined as the date of new asthma diagnosis. We excluded patients with missing age, sex data, and those with stroke (ICD-9-CM 430-438), PD (ICD-9-CM 332), and dementia (ICD-9-CM 290, 294.1, and 331.0) had been diagnosed prior to the diagnosis of COPD, or the patients had cases of asthma before the index date. For each patient with ACOS, two non-ACOS comparison patients were frequency-matched for sex, age (5-year intervals), and ACOS diagnosis year. The index date for patients without ACOS were the date of randomly assigned month and day with the same index year of the patients with ACOS. These patients follow up to diagnosis of stroke, PD and dementia; or the December 31, 2011. The strict policy of the NHIRD data based on the below: 1) nearly $58.4 \%$ of COPD received the PFT in Taiwan. 2) under the policy of releasing long-term prescription and escalating public medical knowledge to prevent over-use of National Insurance Resource, we need follow up the PFT [14]. 3) The policy of releasing long-term prescription with ICSs in COPD and grading of severity of airflow limitation in COPD based on post-bronchodilator forced expiratory volume in 1 second (FEV1) were frequently used in Taiwan [FEV1/forced vital capacity $(\mathrm{FVC})<0.7]$ based on the post-bronchodilator increase in FEV1 $>12 \%$ and $>200-400 \mathrm{ml}$ from baseline [83]. 4) The justification of the drug use of new diagnosis of COPD [84] or Integrated care for geriatric frailty [85] in ACOS cohort based on the PFT is popular in Taiwan. For example, $61 \%$ hypertension and $39.6 \%$ of CAD among the ACOS cohort, we need PFT for evaluation of the beta-blocker use [86] which may be used carefully in the disease containing of the asthma component such as ACOS.

\section{Outcome, comorbidities}

Both ACOS and non-ACOS cohorts were followed until one of the following events occurred: the diagnosis of stroke, PD, or dementia; patient data being censored because of withdrawal from the NHI program; or the end of 2011. The baseline comorbidity history for each participant was determined before index date. The smoking and atopic diseases were associated with the ACOS [49]. Therefore, the preexisting comorbidities-related [87] with smoking [e.g. diabetes (ICD-9-CM 250), hypertension (ICD-9-CM 401-405), hyperlipidemia (ICD-9-CM 272), coronary artery disease (ICD-9-CM 410-414), alcohol-related illness (ICD9-CM 291, 303, 305, 571.0, 571.1, 571.2, 571.3, 790.3, A215, and V11.3), sleep disorder (ICD-9-CM 307.4 and 780.5), anxiety (ICD-9-CM 300.00), cancer (ICD-9-CM 140-208), tuberculosis (ICD-9-CM 010-018), pneumonia (ICD-9-CM 481-486)] and atopic-related diseases were analyzed.

\section{Exposure assessment}

The use of drugs, namely ICSs/OSs [56, 88], was analyzed. The ICSs that were analyzed in this study included fluticasone propionate and budesonide. Information regarding exposure to ICSs was extracted from the prescription database. Users of ICSs/OSs were defined as those who received at least one prescription for ICSs/ OSs between the ACOS diagnosis date and index date. The date of prescription, and number of days supplied were identified. The use of ICSs/OSs were approved in Taiwan in January, 2001 and was placed on the listing of NHI drugs for reimbursement in February, 2002. The (ICSs , OSs) users were defined as patients who received prescription for $\geqq(30,5)$ days, and those who did not receive ICSs/ OSs prescription were classified as nonusers of ICSs/OSs. Any ICSs/OSs, prescribed after index date and before the endpoints for the subjects was considered as exposure. We calculated recorded average dose of ICSs/OSs therapy per year by dividing the total prescribed dose by the follow-up period. The average dose on median use is partitioned in to 3 segments by tertile of ICSs/ OSs. Moreover, we categorized the patients with ICSs used into four groups on the basis of daily equivalent fluticasone doses: no fluticasone use, low dose $(<250 \mu \mathrm{g} / \mathrm{d})$, medium dose $(250-500 \mu \mathrm{g} / \mathrm{d})$, and high dose $(>500 \mu \mathrm{g} / \mathrm{d})$. 


\section{Statistical analysis}

The distribution of characteristics between the ACOS and non-ACOS cohorts showed means and corresponding standard deviations (SDs) for age and determined the number and percentage for sex, age group, comorbidities, and drugs used. The cumulative incidence of stroke, PD, or dementia was assessed using the Kaplan-Meier method, and the curve difference was determined using the log rank test. The incidence density rates of stroke, PD, or dementia stratified by sex, age, comorbidities, and drugs used were calculated in both cohorts. Univariable and multivariable Cox proportional hazards regression models were used to estimate the hazard ratios (HRs) and 95\% confidence intervals (CIs) for stroke, PD, or dementia in the ACOS cohort compared with the non-ACOS cohort. Furthermore, the multivariable Cox proportional hazards regression model was used to estimate the risk of stroke, PD, or dementia on the basis of the drugs used for treatment. SAS Version 9.4 (SAS Institute, Cary, NC, USA) was used for data management and statistical analyses. A two-sided $P$ value of $<.05$ was considered significant.

\section{CONCLUSIONS}

The ACOS cohort had a higher risk of the neurodegenerative diseases. The lower dose of the inhaler corticosteroids with cumulative dose $\geqq 0.13$ gram have the less risk of stroke and dementia.

\section{Abbreviations}

ACOS: asthma-chronic obstructive pulmonary disease syndrome; PD: Parkinson's disease; aHR: adjusted hazard ratio; CI: confidence interval; OS: oral steroid; IC: inhaled corticosteroid; CAD:coronary artery disease; TB: tuberculosis; COPD: chronic obstructive pulmonary disease; NHIRD: National Health Insurance Research Database; LHID 2000: Longitudinal Health Insurance Database 2000; ICD-9- CM: International Classification of Diseases, Ninth Revision, Clinical Modification.

\section{Author contributions}

Conceptualization: W.-H. H. J.-J. Y. Formal analysis: all authors. Investigation: all authors. Writing (original draft preparation): all authors. Writing (review and editing): all authors. Supervision: W.-H. H., J.-J. Y.

\section{ACKNOWLEDGMENTS AND FUNDING}

This study is supported in part by Taiwan Ministry of Health and Welfare Clinical Trial and Research Center of Excellence (MOHW106-TDU-B-212-113004), China Medical University Hospital, Academia Sinica Taiwan Biobank Stroke Biosignature Project (BM10601010036),
NRPB Stroke Clinical Trial Consortium (MOST 1062321-B-039-005), Tseng-Lien Lin Foundation, Taichung, Taiwan, Taiwan Brain Disease Foundation, Taipei, Taiwan, and Katsuzo and Kiyo Aoshima Memorial Funds, Japan. The funders had no role in study design, data collection and analysis, decision to publish, or preparation of the manuscript. No additional external funding received for this study.

\section{CONFLICTS OF INTEREST}

All authors report no conflicts of interest.

\section{REFERENCES}

1. Gray WK, Richardson J, McGuire J, Dewhurst F, Elder V, Weeks J, Walker RW, Dotchin CL. Frailty Screening in Low- and Middle-Income Countries: A Systematic Review. J Am Geriatr Soc. 2016; 64:806-23.

2. Porter Starr KN, McDonald SR, Weidner JA, Bales CW. Challenges in the Management of Geriatric Obesity in High Risk Populations. Nutrients. 2016; 8:8.

3. Liotta G, O'Caoimh R, Gilardi F, Proietti MG, Rocco G, Alvaro R, Scarcella P, Molloy DW, Orlando S, Mancinelli S, Palombi L, Stievano A, Marazzi MC. Assessment of frailty in community-dwelling older adults residents in the Lazio region (Italy): A model to plan regional communitybased services. Arch Gerontol Geriatr. 2017; 68:1-7.

4. Gordon BA, Najmi S, Hsu P, Roe CM, Morris JC, Benzinger TL. The effects of white matter hyperintensities and amyloid deposition on Alzheimer dementia. Neuroimage Clin. 2015; 8:246-52.

5. Shah N, Frey KA, Müller ML, Petrou M, Kotagal V, Koeppe RA, Scott PJ, Albin RL, Bohnen NI. Striatal and Cortical $\beta$-Amyloidopathy and Cognition in Parkinson's Disease. Mov Disord. 2016; 31:111-17.

6. Gong QH, Shi XR, Hong ZY, Pan LL, Liu XH, Zhu YZ. A new hope for neurodegeneration: possible role of hydrogen sulfide. J Alzheimers Dis. 2011; 24:S173-S82.

7. Li CH, Chen WC, Liao WC, Tu CY, Lin CL, Sung FC, Chen $\mathrm{CH}$, Hsu WH. The association between chronic obstructive pulmonary disease and Parkinson's disease: a nationwide population-based retrospective cohort study. QJM. 2015; 108:39-45.

8. Fujita K, Nakabeppu Y, Noda M. Therapeutic effects of hydrogen in animal models of Parkinson's disease. Parkinsons Dis. 2011; 2011:307875.

9. Bozek A, Rogala B, Bednarski P. Asthma, COPD and comorbidities in elderly people. J Asthma. 2016; 53:943-47.

10. King PT. Inflammation in chronic obstructive pulmonary disease and its role in cardiovascular disease and lung cancer. Clin Transl Med. 2015; 4:68.

11. Yeh NC, Tien KJ, Yang CM, Wang JJ, Weng SF. Increased Risk of Parkinson's Disease in Patients With Obstructive Sleep Apnea: A Population-Based, Propensity Score- 
Matched, Longitudinal Follow-Up Study. Medicine (Baltimore). 2016; 95:e2293.

12. Kent BD, Mitchell PD, McNicholas WT. Hypoxemia in patients with COPD: cause, effects, and disease progression. Int J Chron Obstruct Pulmon Dis. 2011; 6:199-208.

13. Kang J, Yao W, Cai B, Chen P, Ling X, Shang H. Current situation of asthma-COPD overlap syndrome (ACOS) in Chinese patients older than 40 years with airflow limitation: rationale and design for a multicenter, cross-sectional trial (study protocol). J Thorac Dis. 2016; 8:3744-51.

14. Yeh JJ, Wang YC, Kao CH. Asthma-Chronic Obstructive Pulmonary Diseases Overlap Syndrome Increases the Risk of Incident Tuberculosis: A National Cohort Study. PLoS One. 2016; 11:e0159012.

15. Yeh JJ, Wei YF, Lin CL, Hsu WH. Association of asthmachronic obstructive pulmonary disease overlap syndrome with coronary artery disease, cardiac dysrhythmia and heart failure: a population-based retrospective cohort study. BMJ Open. 2017; 7:e017657.

16. Yeh JJ, Wang YC, Kao CH. Asthma-Chronic Obstructive Pulmonary Disease Overlap Syndrome Associated with Risk of Pulmonary Embolism. PLoS One. 2016; 11:e0162483.

17. Marcon A, Saugo M, Fedeli U. COPD-Related Mortality and Co-morbidities in Northeastern Italy, 2008-2012: A Multiple Causes of Death Analysis. COPD. 2016; 13:35-41.

18. Chung WS, Lin CL, Kao CH. Comparison of acute respiratory events between asthma-COPD overlap syndrome and COPD patients: a population-based cohort study. Medicine (Baltimore). 2015; 94:e755.

19. Ng AC, Chung T, Yong AS, Wong HS, Chow V, Celermajer DS, Kritharides L. Long-term cardiovascular and noncardiovascular mortality of 1023 patients with confirmed acute pulmonary embolism. Circ Cardiovasc Qual Outcomes. 2011; 4:122-28.

20. Barnes PJ. Therapeutic approaches to asthma-chronic obstructive pulmonary disease overlap syndromes. J Allergy Clin Immunol. 2015; 136:531-45.

21. Ding B, DiBonaventura M, Karlsson N, Ling X. Asthmachronic obstructive pulmonary disease overlap syndrome in the urban Chinese population: prevalence and disease burden using the 2010, 2012, and 2013 China National Health and Wellness Surveys. Int J Chron Obstruct Pulmon Dis. 2016; 11:1139-50.

22. Garin N, Koyanagi A, Chatterji S, Tyrovolas S, Olaya B, Leonardi M, Lara E, Koskinen S, Tobiasz-Adamczyk B, Ayuso-Mateos JL, Haro JM. Global Multimorbidity Patterns: A Cross-Sectional, Population-Based, MultiCountry Study. J Gerontol A Biol Sci Med Sci. 2016; 71:205-14.

23. Katayama Y, Inaba T, Nito C, Ueda M. Neuroprotective effects of erythromycin on ischemic injury following permanent focal cerebral ischemia in rats. Neurol Res. 2016; 38:275-84.

24. Korczyn AD. Vascular parkinsonism-characteristics, pathogenesis and treatment. Nat Rev Neurol. 2015; 11:319-26.
25. Kumbhare S, Pleasants R, Ohar JA, Strange C. Characteristics and Prevalence of Asthma/Chronic Obstructive Pulmonary Disease Overlap in the United States. Ann Am Thorac Soc. 2016; 13:803-10.

26. Shen $\mathrm{CH}$, Chou CH, Liu FC, Lin TY, Huang WY, Wang YC, $\mathrm{Kao} \mathrm{CH}$. Association Between Tuberculosis and Parkinson Disease: A Nationwide, Population-Based Cohort Study. Medicine (Baltimore). 2016; 95:e2883.

27. Liu R, Guo X, Park Y, Wang J, Huang X, Hollenbeck A, Blair A, Chen H. Alcohol Consumption, Types of Alcohol, and Parkinson's Disease. PLoS One. 2013; 8:e66452.

28. Portegies ML, Lahousse L, Joos GF, Hofman A, Koudstaal PJ, Stricker BH, Brusselle GG, Ikram MA. Chronic Obstructive Pulmonary Disease and the Risk of Stroke. The Rotterdam Study. Am J Respir Crit Care Med. 2016; 193:251-58.

29. Lombardi C, Raffetti E, Caminati M, Liccardi G, Passalacqua G, Reccardini F, Ridolo E, Senna G, Steinhilber G, Milanese M, and ELSA Study Group. Phenotyping asthma in the elderly: allergic sensitization profile and upper airways comorbidity in patients older than 65 years. Ann Allergy Asthma Immunol. 2016; 116:206-11.

30. Grandoch M, Roscioni SS, Schmidt M. The role of Epac proteins, novel cAMP mediators, in the regulation of immune, lung and neuronal function. Br J Pharmacol. 2010; 159:265-84.

31. Gibson PG, McDonald VM. Asthma-COPD overlap 2015: now we are six. Thorax. 2015; 70:683-91.

32. Huang AX, Lu LW, Liu WJ, Huang M. Plasma Inflammatory Cytokine IL-4, IL-8, IL-10, and TNF- $\alpha$ Levels Correlate with Pulmonary Function in Patients with Asthma-Chronic Obstructive Pulmonary Disease (COPD) Overlap Syndrome. Med Sci Monit. 2016; 22:2800-08.

33. Frankola KA, Greig NH, Luo W, Tweedie D. Targeting TNF- $\alpha$ to elucidate and ameliorate neuroinflammation in neurodegenerative diseases. CNS Neurol Disord Drug Targets. 2011; 10:391-403.

34. Machado-Silva W, Henriques AD, Souza GD, Gomes L, Ferreira AP, Brito CJ, Córdova C, Moraes CF, Nóbrega OT. Serum Immune Mediators Independently Associate with Atherosclerosis in the Left (But Not Right) Carotid Territory of Older Individuals. J Stroke Cerebrovasc Dis. 2016; 25:2851-58.

35. Kandil EA, Sayed RH, Ahmed LA, Abd El Fattah MA, El-Sayeh BM. Modulatory Role of Nurr1 Activation and Thrombin Inhibition in the Neuroprotective Effects of Dabigatran Etexilate in Rotenone-Induced Parkinson's Disease in Rats. Mol Neurobiol. 2017 Jun 5. https://doi. org/10.1007/s12035-017-0636-x. [Epub ahead of print].

36. Kalinina EP, Denisenko YK, Vitkina TI, Lobanova EG, Novgorodtseva TP, Antonyuk MV, Gvozdenko TA, Knyshova VV, Nazarenko AV. The Mechanisms of the Regulation of Immune Response in Patients with Comorbidity of Chronic Obstructive Pulmonary Disease and Asthma. Can Respir J. 2016; 2016:4503267. 
37. Seifert HA, Collier LA, Chapman CB, Benkovic SA, Willing AE, Pennypacker KR. Pro-inflammatory interferon gamma signaling is directly associated with stroke induced neurodegeneration. J Neuroimmune Pharmacol. 2014; 9:679-89.

38. Barcia C, Ros CM, Annese V, Gómez A, Ros-Bernal F, Aguado-Yera D, Martínez-Pagán ME, de Pablos V, Fernandez-Villalba E, Herrero MT. IFN- $\gamma$ signaling, with the synergistic contribution of TNF- $\alpha$, mediates cell specific microglial and astroglial activation in experimental models of Parkinson's disease. Cell Death Dis. 2011; 2:e142.

39. Rusanen M, Ngandu T, Laatikainen T, Tuomilehto J, Soininen H, Kivipelto M. Chronic obstructive pulmonary disease and asthma and the risk of mild cognitive impairment and dementia: a population based CAIDE study. Curr Alzheimer Res. 2013; 10:549-55.

40. Lee DW, Rajagopalan S, Siddiq A, Gwiazda R, Yang L, Beal MF, Ratan RR, Andersen JK. Inhibition of prolyl hydroxylase protects against 1-methyl-4-phenyl-1,2,3,6tetrahydropyridine-induced neurotoxicity: model for the potential involvement of the hypoxia-inducible factor pathway in Parkinson disease. J Biol Chem. 2009; 284:29065-76.

41. To M, Yamamura S, Akashi K, Charron CE, Haruki K, Barnes PJ, Ito K. Defect of adaptation to hypoxia in patients with COPD due to reduction of histone deacetylase 7 . Chest. 2012; 141:1233-42.

42. Yang QC, Sun X, Wang YM, Wu Q, Feng J, Chen BY. Systematic and endothelial inflammation and endothelial progenitor cell levels in emphysematous rats exposed to intermittent hypoxia. Respir Care. 2015; 60:279-89.

43. Torsney KM, Forsyth D. Respiratory dysfunction in Parkinson's disease. J R Coll Physicians Edinb. 2017; 47:35-39.

44. Buratti L, Viticchi G, Falsetti L, Cagnetti C, Luzzi S, Bartolini M, Provinciali L, Silvestrini M. Vascular impairment in Alzheimer's disease: the role of obstructive sleep apnea. J Alzheimers Dis. 2014; 38:445-53.

45. Bruunsgaard H, Skinhøj P, Pedersen AN, Schroll M, Pedersen BK. Ageing, tumour necrosis factor-alpha (TNFalpha) and atherosclerosis. Clin Exp Immunol. 2000; 121:255-60.

46. Putcha N, Wise RA. Asthma-Chronic Obstructive Pulmonary Disease Overlap Syndrome: Nothing New Under the Sun. Immunol Allergy Clin North Am. 2016; 36:515-28.

47. Kerkhof M, Sonnappa S, Postma DS, Brusselle G, Agustí A, Anzueto A, Jones R, Papi A, Pavord I, Pizzichini E, Popov T, Roche N, Ryan D, et al. Blood eosinophil count and exacerbation risk in patients with COPD. Eur Respir J. 2017; 50:50.

48. Renkema TE, Schouten JP, Koëter GH, Postma DS. Effects of long-term treatment with corticosteroids in COPD. Chest. 1996; 109:1156-62.

49. Park HJ, Byun MK, Kim HJ, Ahn CM, Lee JH, Shin KC, Uh ST, Ra SW, Yoo KH, Jung KS. Asthma-COPD
Overlap Shows Favorable Clinical Outcomes Compared to Pure COPD in a Korean COPD Cohort. Allergy Asthma Immunol Res. 2017; 9:431-37.

50. Kitaguchi Y, Yasuo M, Hanaoka M. Comparison of pulmonary function in patients with COPD, asthma-COPD overlap syndrome, and asthma with airflow limitation. Int J Chron Obstruct Pulmon Dis. 2016; 11:991-97.

51. Suzuki T, Tada Y, Kawata N, Matsuura Y, Ikari J, Kasahara Y, Tatsumi K. Clinical, physiological, and radiological features of asthma-chronic obstructive pulmonary disease overlap syndrome. Int J Chron Obstruct Pulmon Dis. 2015; 10:947-54.

52. Feng JX, Lin Y, Lin J, He SS, Chen MF, Wu XM, Xu YZ. Relationship between Fractional Exhaled Nitric Oxide Level and Efficacy of Inhaled Corticosteroid in AsthmaCOPD Overlap Syndrome Patients with Different Disease Severity. J Korean Med Sci. 2017; 32:439-47.

53. Liu SF, Kuo HC, Lin MC, Ho SC, Tu ML, Chen YM, Chen YC, Fang WF, Wang CC, Liu GH. Inhaled corticosteroids have a protective effect against lung cancer in female patients with chronic obstructive pulmonary disease: a nationwide population-based cohort study. Oncotarget. 2017; 8:29711-21. https://doi.org/10.18632/ oncotarget. 15386.

54. Dodd JW. Lung disease as a determinant of cognitive decline and dementia. Alzheimers Res Ther. 2015; 7:32.

55. Wedzicha JA. Eosinophils as Biomarkers of Chronic Obstructive Pulmonary Disease Exacerbation Risk. Maybe Just for Some? Am J Respir Crit Care Med. 2016; 193:93738.

56. Reddel HK. Treatment of overlapping asthma-chronic obstructive pulmonary disease: can guidelines contribute in an evidence-free zone? J Allergy Clin Immunol. 2015; 136:546-52.

57. Waljee AK, Rogers MA, Lin P, Singal AG, Stein JD, Marks RM, Ayanian JZ, Nallamothu BK. Short term use of oral corticosteroids and related harms among adults in the United States: population based cohort study. BMJ. 2017; 357:j1415.

58. Leuppi JD, Schuetz P, Bingisser R, Bodmer M, Briel M, Drescher T, Duerring U, Henzen C, Leibbrandt Y, Maier S, Miedinger D, Müller B, Scherr A, et al. Short-term vs conventional glucocorticoid therapy in acute exacerbations of chronic obstructive pulmonary disease: the REDUCE randomized clinical trial. JAMA. 2013; 309:2223-31.

59. Kurkowska-Jastrzebska I, Litwin T, Joniec I, Ciesielska A, Przybyłkowski A, Członkowski A, Członkowska A. Dexamethasone protects against dopaminergic neurons damage in a mouse model of Parkinson's disease. Int Immunopharmacol. 2004; 4:1307-18.

60. Alisky JM. Intrathecal corticosteroids might slow Alzheimer's disease progression. Neuropsychiatr Dis Treat. 2008; 4:831-33.

61. Lin CF, Lin CM, Lee KY, Wu SY, Feng PH, Chen KY, Chuang HC, Chen CL, Wang YC, Tseng PC, Tsai TT. 
Escape from IFN- $\gamma$-dependent immunosurveillance in tumorigenesis. J Biomed Sci. 2017; 24:10.

62. Raymakers AJ, McCormick N, Marra CA, Fitzgerald JM, Sin D, Lynd LD. Do inhaled corticosteroids protect against lung cancer in patients with COPD? A systematic review. Respirology. 2017; 22:61-70.

63. Barnes PJ. Asthma-COPD Overlap. Chest. 2016; 149:7-8.

64. Yamauchi Y, Yasunaga H, Matsui H, Hasegawa W, Jo T, Takami K, Fushimi K, Nagase T. Comparison of in-hospital mortality in patients with COPD, asthma and asthma-COPD overlap exacerbations. Respirology. 2015; 20:940-46.

65. Bateman ED, Hurd SS, Barnes PJ, Bousquet J, Drazen JM, FitzGerald M, Gibson P, Ohta K, O’Byrne P, Pedersen SE, Pizzichini E, Sullivan SD, Wenzel SE, Zar HJ. Global strategy for asthma management and prevention: GINA executive summary. Eur Respir J. 2008; 31:143-78.

66. Baraket M, Oliver BG, Burgess JK, Lim S, King GG, Black $\mathrm{JL}$. Is low dose inhaled corticosteroid therapy as effective for inflammation and remodeling in asthma? A randomized, parallel group study. Respir Res. 2012; 13:11.

67. Slats A, Taube C. Asthma and chronic obstructive pulmonary disease overlap: asthmatic chronic obstructive pulmonary disease or chronic obstructive asthma? Ther Adv Respir Dis. 2016; 10:57-71.

68. Caillaud D, Chanez P, Escamilla R, Burgel PR, CourtFortune I, Nesme-Meyer P, Deslee G, Perez T, Paillasseur JL, Pinet C, Jebrak G, Roche N, and Initiatives BPCO scientific committee and investigators. Asthma-COPD overlap syndrome (ACOS) vs 'pure' COPD: a distinct phenotype? Allergy. 2017; 72:137-45.

69. Barnes PJ. Corticosteroid resistance in patients with asthma and chronic obstructive pulmonary disease. J Allergy Clin Immunol. 2013; 131:636-45.

70. Zhai Y, Zhang H, Sun T, Ye M, Liu H, Zheng R. Comparative Efficacies of Inhaled Corticosteroids and Systemic Corticosteroids in Treatment of Chronic Obstructive Pulmonary Disease Exacerbations: A Systematic Review and MetaAnalysis. J Aerosol Med Pulm Drug Deliv. 2017; 30:289-98.

71. Barrecheguren M, Román-Rodríguez M, Miravitlles M. Is a previous diagnosis of asthma a reliable criterion for asthma-COPD overlap syndrome in a patient with COPD? Int J Chron Obstruct Pulmon Dis. 2015; 10:1745-52.

72. Baarnes CB, Kjeldgaard P, Nielsen M, Miravitlles M, Ulrik $\mathrm{CS}$. Identifying possible asthma-COPD overlap syndrome in patients with a new diagnosis of COPD in primary care. NPJ Prim Care Respir Med. 2017; 27:16084.

73. Spyratos D, Chloros D, Sichletidis L. Diagnosis of chronic obstructive pulmonary disease in the primary care setting. Hippokratia. 2012; 16:17-22.

74. Cheng SL, Chan MC, Wang CC, Lin CH, Wang HC, Hsu JY, Hang LW, Chang CJ, Perng DW, Yu CJ. COPD in Taiwan: a National Epidemiology Survey. Int J Chron Obstruct Pulmon Dis. 2015; 10:2459-67.

75. Quint JK, Müllerova H, DiSantostefano RL, Forbes H, Eaton S, Hurst JR, Davis K, Smeeth L. Validation of chronic obstructive pulmonary disease recording in the Clinical Practice Research Datalink (CPRD-GOLD). BMJ Open. 2014; 4:e05540.

76. Lucas AE, Smeenk FJ, Smeele IJ, van Schayck OP. Diagnostic accuracy of primary care asthma/COPD working hypotheses, a real life study. Respir Med. 2012; 106:115863.

77. Slack MK, Draugalis JR. Establishing the internal and external validity of experimental studies. Am J Health Syst Pharm. 2001; 58:2173-81.

78. Boffetta P. Internal and external validity of cohort studies. Ann Agric Environ Med. 2011; 18:283-84.

79. Tofthagen C. Threats to validity in retrospective studies. J Adv Pract Oncol. 2012; 3:181-83.

80. Yeh JJ, Wang YC, Hsu WH, Kao CH. Incident asthma and Mycoplasma pneumoniae: A nationwide cohort study. J Allergy Clin Immunol. 2016; 137:1017-1023.e6.

81. Jackson EA, Sivasubramian R, Spencer FA, Yarzebski J, Lessard D, Gore JM, Goldberg RJ. Changes over time in the use of aspirin in patients hospitalized with acute myocardial infarction (1975 to 1997): a population-based perspective. Am Heart J. 2002; 144:259-68.

82. Yeh JJ, Wang YC, Chen JH, Hsu WH. Effect of Systemic Lupus Erythematosus on the Risk of Incident Respiratory Failure: A National Cohort Study. PLoS One. 2016; 11:e0163382.

83. Wei YF, Kuo PH, Tsai YH, Tao CW, Cheng SL, Lee CH, Wu YK, Chen NH, Hsu WH, Hsu JY, Lin MS, Wang CC. Factors associated with the prescription of inhaled corticosteroids in GOLD group A and B patients with COPD - subgroup analysis of the Taiwan obstructive lung disease cohort. Int J Chron Obstruct Pulmon Dis. 2015; 10:1951-56.

84. Chiang $\mathrm{CH}$, Liu SL, Chuang $\mathrm{CH}$, Jheng YH. Effects of guideline-oriented pharmacotherapy in patients with newly diagnosed COPD: a prospective study. Wien Klin Wochenschr. 2013; 125:353-61.

85. Chan DD, Tsou HH, Chang CB, Yang RS, Tsauo JY, Chen CY, Hsiao CF, Hsu YT, Chen CH, Chang SF, Hsiung CA, Kuo KN. Integrated care for geriatric frailty and sarcopenia: a randomized control trial. J Cachexia Sarcopenia Muscle. 2017; 8:78-88.

86. Morales DR, Lipworth BJ, Donnan PT, Jackson C, Guthrie B. Respiratory effect of beta-blockers in people with asthma and cardiovascular disease: population-based nested case control study. BMC Med. 2017; 15:18.

87. Yeh CC, Wang HH, Chou YC, Hu CJ, Chou WH, Chen TL, Liao CC. High risk of gastrointestinal hemorrhage in patients with epilepsy: a nationwide cohort study. Mayo Clin Proc. 2013; 88:1091-98.

88. Green BJ, Wiriyachaiporn S, Grainge C, Rogers GB, Kehagia V, Lau L, Carroll MP, Bruce KD, Howarth PH. Potentially pathogenic airway bacteria and neutrophilic inflammation in treatment resistant severe asthma. PLoS One. 2014; 9:e100645. 